\title{
LITERASI DIGITAL SEBAGAI PENGUATAN PENDIDIKAN KARAKTER MENUJU ERA SOCIETY 5.0
}

\author{
Bambang Yuniarto, Rivo Panji Yudha \\ IAIN Syekh Nurjati Cirebon, Universitas 17 Agustus 1945 Cirebon \\ Email: Bb_yunior@yahoo.co.id; rivoyudha@yahoo.co.id
}

\begin{abstract}
ABSTRAK
Artikel ini merupakan hasil pemikiran tentang pentingnya literasi digital untuk penguatan pendidikan karakter di era sosial 5.0. Pendidikan kewarganegaraan merupakan bagian yang sangat diperlukan, yang tercermin pada semua jenjang pendidikan dan kursus serta bentuk pembelajaran di berbagai bidang. Dalam rangka pencapaian tujuan pendidikan nasional, berbagai fungsi dan peran pendidikan kewarganegaraan dirancang dan diwujudkan sebagai perwujudannya. Di era Society 5.0, kewarganegaraan mutlak diperlukan, menuntut masyarakat untuk menguasai dan menyeimbangkan kemampuan kecerdasan buatan dan kecerdasan sosial untuk menyelesaikan berbagai persoalan bangsa. Society 5.0 memberikan contoh bagaimana data dapat digunakan untuk memobilisasi dan menghubungkan segala hal, termasuk upaya mengatasi masalah sosial. Singkatnya, siswa memiliki keterampilan yang dibutuhkan di era society 5.0, ini termasuk: kepemimpinan, literasi digital, komunikasi, kecerdasan emosional, kewirausahaan, dan kewarganegaraan global. Tantangan pendidikan kewarganegaraan adalah memberikan pengetahuan dan keterampilan berpikir kritis, konstruktif, dan kreatif tanpa meninggalkan kearifan emosional, sosial, dan spiritual Pancasila dan UUD 1945.
\end{abstract}

\section{Kata Kunci: Literasi Digital, Karakter, Society 5.0}

\begin{abstract}
This article is the result of thinking about the importance of digital literacy for strengthening character education in the social 5.0 era. Civic education is an inseparable part and is reflected in the courses and learning forms of all levels of education and various fields. Within the framework of achieving the goals of national education, various functions and roles of civic education are designed and realized as manifestations. In the 5.0 era, citizenship is absolutely necessary. It requires people to master and balance the capabilities of artificial intelligence and social intelligence to solve various problems in the country. Society 5.0 provides an example of how to use data to mobilize and connect everything, including efforts to solve social problems. In short, students have the skills needed in the Social 5.0 era, including: leadership, digital literacy, communication, emotional intelligence, entrepreneurship, and global citizenship. The challenge of civic education is to provide the knowledge and skills of critical, constructive and creative thinking without departing from the emotional, social and spiritual wisdom of Pancasila and the 1945 Constitution.
\end{abstract}

Keywords: Digital Literacy, Character, Society 5.0

Jurnal Edueksos Vol. X, No. 2, Desember 2021

The journal of social and economic education 


\section{A. PENDAHULUAN}

Menyikapi pesatnya era pendidikan 4.0. Sebagai negara maju di bidang teknologi, Jepang telah mengedepankan konsep society 5.0. Merebaknya Covid-19 di dunia, maka mengharuskan setiap orang melakukan jarak fisik termasuk pendidikan. Namun di Jepang sudah memasuki era society 5.0. Konsep society 5.0 tidak hanya terbatas pada faktor manufaktur tetapi juga memecahkan masalah sosial dengan bantuan integrasi ruang fisik dan virtual. Society 5.0 memiliki konsep teknologi big data yang dikumpulkan oleh internet of things (IoT) menjadi Artificial Intelligence (AI) (Hayashi et al. 2017).

Society 5.0 akan berdampak pada semua aspek kehidupan, termasuk kesehatan, tata kota, transportasi, pertanian, industri dan pendidikan (Özdemir and Hekim 2018). Ke depan, teknologi bigdata yang dihimpun menurut society 5.0 juga berdampak positif dan negatif dalam aspek pendidikan nasional Indonesia.

Pendidikan di era digital saat ini sangat cepat, perkembangan inovasi tidak hanya disukai oleh orang dewasa, anak-anak sekolah dasar juga dapat mengambil bagian dalam dampak dari perubahan mekanis saat ini. Inovasi digunakan secara luas dalam bidang pengajaran, sebagai metode dan landasan untuk asosiasi antara pengajar dan siswa. Kemajuan mekanis saat ini memiliki konsekuensi positif dan negatif, efek positifnya harus lebih banyak digunakan oleh klien inovasi.

Salah satu makna dasar dari tantangan society 5.0 adalah konten pendidikan. Pesatnya perkembangan teknologi menuntut sektor pendidikan mampu beradaptasi dengan digitalisasi sistem pendidikan yang terus berkembang. Menjawab tantangan era society 5.0, mengemas secara cermat dan mempersiapkan diri untuk maju mengikuti perkembangan zaman. Dalam mempersiapkan tantangan era society 5.0, desain kurikulum pendidikan menyebutkan beberapa poin substantif: 1) pendidikan karakter; 2) memiliki kemampuan berpikir kritis, inovatif dan inovatif; 3) mampu mengaplikasikan teknologi pada era tersebut.

Pedoman tersebut bergantung pada pekerjaan orang itu sendiri beserta inovasi yang telah dibuat, sehingga orang mendapatkan keselarasan antara kemajuan keuangan dan penanganan masalah sosial melalui kerangka kerja yang sangat terkait melalui dunia maya dan kenyataan saat ini. Misalnya seperti yang tergambar 
di social media IAIN Syekhnurjati Cirebon, dugaan relasi revolusi industri 4.0 dan society 5.0, misalnya, pemanfaatan Informasi Besar yang mengikuti perkembangan society 5.0 bisa di berbagai bidang. Society 5.0 sendiri merupakan pemikiran yang diangkat sebagai bahan perbincangan pada World Financial Gathering awal Januari 2019 di Davos, Swiss. Menurut kepala administrator Jepang, Shinzo Abe mengatakan bahwa gagasan pergolakan modern 4.0 dan society 5.0 tidak memiliki banyak kontras. Secara khusus, revoulusi modern 4.0 memanfaatkan penalaran buatan manusia sementara society 5.0 menyoroti komponen manusia (Rahman 2019).

Selanjutnya, dukungan dan peran pendidikan diandalkan untuk memperluas keseriusan negara di tengah persaingan dunia, peningkatan pesat inovasi data. Gelombang besar dunia digital saat ini tanpa henti, yang mengirim setiap individu yang dapat menggunakannya namun secara teratur dapat melenyapkan martabat seseorang dengan cara yang berbeda. Ketidaktahuan manusia di dunia digital menyebabkan berbagai perlakuan buruk terhadap media digital terjadi di level personal, sosial dan nasional. Oleh karena itu, peningkatan kualitas pembelajaran merupakan salah satu tantangan bagi para pelaku pendidikan di Indonesia.

Paul Gilster menciptakan istilah literasi digital pada tahun 1977 (English 2016). Teknologi telah menjadi bagian integral dari kehidupan siswa, tetapi kemampuan digital tidak selalu diperkenalkan di ruang kelas pendidikan tinggi (Nelson, Courier, and Joseph 2011). Perkembangan kapabilitas digital tidak terjadi secara spontan (English 2016). Oleh karena itu, penting untuk mengembangkan kemampuan digital agar siswa dapat menggunakan media digital untuk mengkomunikasikan dan mengekspresikan gagasannya secara efektif (Chan, Churchill, and Chiu 2017). Salah satu cara untuk memulainya adalah dengan memasukkan penggunaan produk digital ke dalam komposisi literasi dan pengajaran, yang akan membantu mempromosikan literasi digital (Traxler 2018).

Konsep revolusi yang digagas di Jepang lebih mendorong peran manusia dalam mengatasi paradigma kemajuan revolusi industri 4.0. Artinya di era masyarakat 5.0, manusia dituntut untuk memiliki kemampuan lebih dalam memecahkan masalah yang kompleks, berpikir kritis, dan kreatif. Ketersediaan tren 
teknologi tinggi dalam otomatisasi dan pertukaran data selama revolusi industri 4.0 seperti sistem cyber-fisik, internet of things, komputasi awan, dan komputasi kognitif. Sehingga dengan hadirnya Society 5.0 dapat menjadi solusi dari hal di atas, bukan untuk menyaingi apa yang sudah ada sebelumnya pada revolusi industri 4.0 .

Literasi satuan pendidikan tidak dapat menghalangi kerja sama dengan berbagai institusi, jaringan, dan jaringan di luar iklim sekolah. Asosiasi publik diperlukan mengingat sekolah tidak dapat menjalankan visi dan misinya sendiri. Oleh karena itu, berbagai jenis upaya terkoordinasi dan kolaborasi antara jaringan dan unit pembelajaran di luar sekolah diperlukan dalam memperkuat pelatihan karakter. Ada berbagai jenis upaya terkoordinasi yang dapat dilakukan dalam rangka menciptakan pendidikan karakter bagi siswa dalam menghadapi pelatihan abad ke-21, khususnya kerjasama dengan Menkominfo, maupun organisasi lainorganisasi lain sebagai pegiat literasi digital (Komara 2018).

Seperti yang dikatakan Alhefeiti (2018), meskipun society 5.0 berpusat pada manusia, society 5.0 merupakan upaya untuk menjadi masyarakat yang berorientasi pada masyarakat berintegrasi dunia nyata dan virtual. Raharja (2019) menyatakan bahwa society 5.0 masih berkaitan erat menggunakan Industri 4.0, tetapi teknologi di society 5.0 lebih menunjuk dalam kehidupan sosial.. (Alhefeiti 2018; Raharja 2019).

Mengunakan media digital atau berinteraksi di dunia digital haruslah tetap mengindahkan aturan yang ada, serta norma yang berlaku di masyarakat (Beasley, 2013). Selain itu, masyarakat digital harus memiliki literasi digital. Literasi digital adalah tentang menggunakan media digital, alat atau jaringan komunikasi untuk menemukan, mengevaluasi, menggunakan, memproduksi dan menggunakan keterampilan atau pengetahuan informasi secara baik, bijak, cerdas, teliti, seksama \& taat hukum. Untuk mempromosikan komunikasi \& hubungan pada kehidupan sehari-hari (Gillen 2014).

Jimoyiannis, A., dan Gravani, M. (2011) menyatakan bahwa peran literasi digital dalam program pendidikan sangat penting, karena bertujuan untuk membantu siswa dalam mencapai hal-hal berikut: memperoleh informasi khusus 
dan kemampuan yang diharapkan. untuk berhasil memanfaatkan media komputerisasi, terampil dalam memanfaatkan media canggih. media terkomputerisasi untuk mengatasi masalah kehidupan sehari-hari, memahami ukuran sosial dan efek media canggih dalam masyarakat mutakhir kita, dan mengembangkan pandangan yang menggembirakan tentang media canggih dan menghadapi permintaan zaman sekarang (Jimoyiannis and Gravani 2011).

Menjadi melek digital bagi guru dalam pengajaran digital adalah dasar karena alat digital secara fundamental mengubah sifat pengetahuan dalam arti bahwa mereka memungkinkan cara yang lebih kreatif, aktif, kolektif, dan pribadi dalam membangun dan mengkomunikasikan pengetahuan melalui media digital (McDougall, Readman, and Wilkinson 2018). Sementara itu, Olsson dan EdmanStålbrant (2008) menyatakan bahwa seorang mentor pendidik harus dapat: 1) menyimpulkan jenis alat digital apa yang tepat untuk konten kursus mereka dan dapat memperkenalkan kursus mereka di web, 2) mencari tahu apa jenis instrumen canggih dan metode kerja yang membantu, menciptakan atau mengerjakan karakter mereka, 3) mewujudkan biaya dengan beragam tes lanjutan sehingga mereka dapat memilih jenis penilaian terbaik sesuai tujuan dan aturan, dan 4) menjelaskan dan menampilkan pendidikan dan masalah pembelajaran, untuk siswa, sesuai dengan instrumen dan strategi terkomputerisasi yang dipilih (Olsson and Edman-Stålbrant 2008). Di era digital, para pendidik dituntut untuk tetap waspada terhadap pergantian peristiwa secara mekanis, oleh karena itu, meskipun menunjukkan kemampuan yang luas, beberapa kemampuan tambahan seharusnya sudah tertanam dalam diri seorang instruktur untuk menjalankan perannya secara memadai sebagai fasilitator pembelajaran. Irianti (2020) menjelaskan bahwa ada lima kemampuan sebagai fasilitator perolehan bagi instruktur dalam melaksanakan pembelajaran lanjutan, khususnya kemampuan mengorganisir, kemampuan relasional, kemampuan berpikir, kemampuan mempertahankan, dan papan informasi (Irianti 2020).

Tentunya setiap orang yang berinteraksi di dunia digital harus memiliki skill literasi digital ini. Jika tidak, ini dapat mengancam pengguna media digital, misalnya mudah tersinggung atau terganggu, termakan oleh hoax, tertipu, diretas 
atau pencurian data, dll (Fitriarti 2019). Begitu banyak kejahatan yang bisa dilakukan di dunia maya. Bahkan mungkin lebih besar lagi, karena di dunia digital banyak orang yang menggunakan akun palsu (Fake Account) dan banyak orang asing yang belum tentu saling mengenal atau mengenal (Rohman 2016).

Jika hanya didasarkan pada literasi dan cara penggunaan internet (khususnya media digital), literasi digital tidak akan berfungsi secara maksimal. Namun harus dibarengi dengan budi pekerti yang baik dan perilaku yang baik dalam media komunikasi digital itu sendiri. Apalagi di media sosial, komunitasnya sangat beragam, dengan latar belakang yang berbeda-beda.

Terkait pentingnya menyiapkan generasi masa depan yang memiliki karakter unggul serta kemampuan menjawab tantangan di masanya, maka artikel ini akan membahas tentang "Literasi Digital Sebagai Penguatan Pendidikan Karakter Menuju Era society 5.0.

\section{B. METODE}

Penelitian ini merupakan penelitian kualitatif dengan metode studi kepustakaan. Objek kajian berfokus pada analisis buku, artikel ilmiah, dan sumber literasi lainnya yang terkait dengan pentingnya pendidikan karakter berbasis literasi digital pada siswa sekolah dasar Analisis data dilakukan dengan mengkaji proses pengauatan karakter yang bersumber dari literasi digital. Dengan demikian maka penelitian ini menemukan proses, upaya dan antisipasi membentuk karakter siswa, agar dapat melahirkan generasi bangsa yang survive dan berbudi pekerti. Pengecekan data dalam penelitian ini dilakukan dengan menggunakan bahan pustaka (referensi).

\section{HASIL DAN PEMBAHASAN}

Pemerintah dan pembuat kebijakan menyadari pentingnya teknologi digital untuk tujuan pendidikan. Kampanye literasi nasional direncanakan untuk mempromosikan pendidikan di Indonesia. Literasi digital merupakan salah satu pendidikan literasi, dan merupakan salah satu indikator penting untuk mendorong perkembangan dunia pendidikan. Dampak pertumbuhan sumber daya digital dengan peluang akses yang luas dan keterbukaan merupakan indikator penting peningkatan kualitas pendidikan (Altınay et al. 2016). Perubahan teknologi dan 
ledakan informasi telah mengubah dimensi proses pembelajaran (Çam and Kiyici 2017). Hal ini mendorong banyak orang untuk mengembangkan kemampuan digital agar dapat mengelola secara efisien dalam dunia digital multidimensi yang berubah dengan cepat, terutama bagi kaum milenial (Kirchoff 2017).

Namun dengan perkembangan ilmu pengetahuan sekarang ini pendidikan karakter semakin sulit untuk ditanamkan pada siswa, oleh karena itu pendidikan karakter sangat penting untuk diterapkan di sekolah-sekolah mengingat semakin maju siswa pendidikan karakter, semakin banyak siswa yang mengikuti perilaku buruk. yang berasal dari komunikasi luas, web, dan media berbasis web. permainan, terutama saat ini latihan belajar menggunakan internet semakin mempengaruhi instruksi siswa. Pasca pandemi virus corona, pembelajaran karakter siswa tidak dapat dicek langsung oleh pengajar sehingga pelatihan siswa yang telah ditanamkan di sekolah-sekolah semakin berkurang, terkait hubungannya dengan proses pembelajaran berbasis digital juga mempengaruhi siswa yang lugas, terkendali, mentalitas bebas, dan mampu dalam minat belajar latihan seperti halnya dalam mengurus tugas, oleh karena itu orang tua berperan penting dalam membentuk pembelajaran karakter siswa selama pandemi, orang tua membantu anak-anaknya melakukan latihan belajar, selama latihan belajar orang tua melaporkan latihan anak-anak mereka kepada wali kelas (Awulloh and Latifah 2021).

Munculnya mobilitas, perangkat digital telah menjadi bagian tak terpisahkan dari kehidupan manusia, dan tiga faktor penting telah ditingkatkan, seperti kecepatan, virtualitas, dan jaringan. (Ozdamar-Keskin et al. 2020). Produk digital dinilai telah memberikan kontribusi positif untuk praktik pengajaran yang lebih baik (Robertson et al. 2004; Wang 2008). Siswa menggunakan teknologi digital untuk kegiatan pembelajaran, seperti membaca dan mengirim pesan, mengakses sistem manajemen pembelajaran, membaca e-book dan majalah, berpartisipasi dalam forum, dll (Jones et al. 2010). Meskipun siswa saat ini secara umum diyakini paham teknologi, banyak dari mereka masih merasa kesulitan untuk menggunakan teknologi secara efektif (Tang and Chaw 2016). Sebagai pengguna produk digital, siswa adalah pengguna teknis yang paling aktif, tetapi mereka juga merupakan pengguna yang paling rentan (Gruszczynska, Merchant, and Pountney 2013). 
Literasi digital didefinisikan sebagai memiliki kemampuan umum untuk menggunakan komputer selain keterampilan seperti menggunakan pengolah kata atau perangkat lunak database, tanpa melibatkan dimensi sosial budaya literasi digital (Gruszczynska et al. 2013). Keaksaraan melibatkan kesinambungan pembelajaran, dimana individu dapat mencapai tujuan, mengembangkan pengetahuan, merealisasikan potensinya dan berpartisipasi penuh dalam seluruh komunitas dan masyarakat secara keseluruhan. (Çam and Kiyici 2017). Literasi digital berarti jalan masuk ke berbagai adat dan sumber daya budaya yang dapat diterapkan pada perangkat digital (Hague and Payton 2010). Kemampuan untuk membuat dan berbagi arti dari berbagai pola dan format; secara efektif membuat, berkolaborasi dan berkomunikasi, serta memahami bagaimana dan kapan menggunakan teknologi digital (Son, Park, and Park 2017).

Penggunaan media digital untuk tujuan pendidikan dianggap sebagai langkah untuk mempersiapkan dan meningkatkan generasi muda di era globalisasi (Ismail 2015). Literasi digital, literasi media dan literasi informasi memainkan peran penting dalam pendidikan dasar, menengah dan tinggi (Koltay 2011). Untuk mencapai tujuan tersebut diperlukan keterampilan, terutama keterampilan literasi, karena keterampilan literasi telah memainkan peran penting dalam sistem pendidikan di banyak negara dengan merumuskan kurikulum, tujuan dan sasaran (Çam and Kiyici 2017). Hasilnya, departemen pendidikan di seluruh dunia mulai memasukkan literasi digital ke dalam kurikulum mereka (Chan et al. 2017).

Kesadaran masyarakat tentang literasi digital biasanya terbatas pada penggunaan aktual produk digital, seperti smartphone, tablet, komputer, dan beberapa aplikasi pendukung lainnya (Kennedy et al. 2008). Para ahli menyarankan bahwa konsep literasi digital sedikit berbeda. Dengan definisi yang berbeda, literasi digital dapat dianggap sebagai kemampuan membaca, menulis, melihat, mendengarkan, dan mengkomunikasikan informasi (Bawden 2008). Bentuk jamak dari kata literaci merupakan langkah yang disengaja untuk memperluas konsep literasi dengan menggabungkan beberapa simbologi (Song 2017). Di bidang pendidikan teknologi, sub disiplin literasi digital meliputi literasi komputer, literasi 
teknologi, literasi informasi, literasi media, literasi visual, dan literasi komunikasi (Goodfellow 2011).

Kunci utamanya adalah literasi digital. Pemerintah harus bekerja keras untuk meningkatkan kesadaran setiap orang agar memiliki pemahaman tentang bagaimana menggunakan media sosial dengan bijak dan bagaimana mengekspresikan diri di dunia digital. Tingkat pendidikan juga mempengaruhi kemampuan seseorang untuk menganalisis, mengevaluasi, dan merangkum berbagai isu atau berita yang berkembang. Mana yang benar, mana yang bohong, mana yang baik dan mana yang buruk. Setiap pengguna media sosial atau orang yang berinteraksi di dunia digital harus menguasai kemampuan ini.

Pemerintah telah banyak mengeluarkan kebijakan dasar hingga lanjutan di bidang pendidikan. Namun regulasi pendidikan harus memberikan kebebasan dan perlindungan bagi setiap pendidik. Hal ini dikarenakan tenaga pengajar telah mengalami banyak kejadian sepele, sehingga dikatakan tenaga pengajar gagal membentuk karakter siswa. Dalam penerapan pendidikan karakter, setidaknya semua pihak baik pendidik, keluarga, masyarakat, polisi dan organisasi kemasyarakatan berperan dalam proses pendidikan karakter. Pembentukan karakter atau kepribadian setiap siswa tidak hanya dilakukan di lingkungan formal, tetapi juga dapat diterapkan di lingkungan informal yang dapat merangsang pembentukan karakter pribadi.

Selain itu, dalam interaksi dunia digital juga perlu dilakukan penguatan role education. Namun literasi digital harus didukung oleh sikap dan niat yang baik. Sikap dan niat baik ini dikembangkan melalui pendidikan karakter. Pendidikan karakter bangsa Indonesia telah berakar pada landasan negara Indonesia yaitu Pancasila. Selain itu juga didukung oleh pendidikan agama yang memungkinkan setiap orang memahami perilaku yang baik dan menciptakan perdamaian. Sebaliknya, umat beragama mudah terprovokasi.

Selain itu, Anda harus memiliki kepribadian yang kuat dalam perilaku masyarakat di media sosial. Tentunya umat beragama harus memiliki akhlak atau sikap yang baik sesuai dengan norma yang berlaku. Jika orang beragama menghina diri sendiri di media sosial, itu akan menjadi fenomena yang aneh. Untuk itu, sudah 
saatnya menumbuhkan karakter atau perilaku yang baik di media sosial berdasarkan sense of digital literacy ini.

Dalam literasi digital itu sendiri, kita juga harus mengembangkan sikap atau perilaku yang baik agar literasi digital dapat berjalan dengan normal. Literasi digital harus mengembangkan kapabilitas khalayak, dalam hal ini pendidikan literasi media dalam memahami tipikal informasi atau informasi media. Selain itu juga dibarengi dengan perkembangan tingkah laku, seperti perkembangan emosi, perasaan perasaan orang lain yaitu sikap empati dalam memahami informasi. Ini dalam bentuk kematangan moral untuk menahan terjadinya konsekuensi moral. Dengan cara ini, Anda dapat memahami hal-hal buruk yang mungkin terjadi pada informasi yang disebarkan dan cara menghadapinya (Adyawanti, Pendahuluan, and Pusat 2016).

Pendidikan karakter sekolah telah dilaksanakan dengan sistem yang sangat baik. Hal ini terlihat dari adanya pendidikan karakter yang komprehensif, misalnya setiap kemampuan dasar yang diwujudkan dalam pembelajaran di kelas termasuk pendidikan karakter. Ini termasuk pendidikan karakter di luar kelas dan kegiatan ekstrakurikuler seperti pengintaian dan seni (Kurniawan 2015).

Pendidikan karakter di lingkungan rumah atau keluarga masih belum ideal. Beberapa orang tua masih belum optimal mengontrol akan pentingnya pembentukan karakter. Padahal pendidikan karakter di lingkungan keluarga sangatlah baik dan memiliki peran dan kedudukan yang kuat dalam pembentukan karakter anak (Purandina 2020). Pendidikan karakter semacam ini memang harus familiar, mengenal dengan kegiatan sehari-hari yang dilakukan dalam bentuk perilaku keluarga sehari-hari, seperti berbicara sopan, bertingkah laku baik, menjaga lingkungan, menjaga ketertiban, dll. Pada dasarnya hal ini harus diikutsertakan dalam setiap aktivitas keluarga dalam kehidupan sehari-hari (Yoga Purandina and Astra Winaya 2020).

Selanjutnya terkait permasalahan dan tantangan yang terjadi di era digital antara lain terkait dengan sikap dan perilaku manusia (Atiah 2020; Nana and Surahman 2019; Ramdani et al. 2020). iri-cirinya antara lain: (1) menyukai kebebasan; (2) suka mempersonalisasi; (3) mengandalkan kecepatan informasi 
yang instan (ready to serve); (4) suka belajar; (5) bekerja dalam lingkungan yang inovatif, (6) berkolaborasi secara aktif, dan (7) hyper technology (8) kritis, yaitu terbiasa berpikir out of the box, kaya akan ide dan gagasan; (9) percaya diri, yaitu memiliki kemampuan yang tinggi untuk menyampaikan pendapat dengan percaya diri tanpa ragu-ragu; (10) connected, yaitu generasi yang pandai bersosialisasi, terutama di komunitas yang diikutinya; (11) berselancar di media sosial dan internet (12) akibat ketergantungan mereka yang tinggi terhadap internet dan media sosial, mereka menjadi malas, tidak dalam, membumi, atau tidak bersosialisasi; (13) cenderung lemah dalam nilai-nilai kebersamaan, gotong royong, kehangatan lingkungan dan kepedulian sosial; (Andriani and Rasto 2019; Atarodi et al. 2021) cenderung bebas, kebarat-baratan dan tidak memperhatikan etika dan aturan formal, adat istiadat, dan tata krama.

Indoktrinasi karakter nilai nasionals merupakan wujud bagaimana berperilaku yang mengedepankan Kebutuhan atau kepentingan negara dan negara lebih tinggi dari pada kepentingan individu dan kelompok. Beberapa nilai sekunder dapat ditemukan dalam perilaku siswa yang menghargai nilai-nilai kebangsaan lain, menjunjung tinggi budaya bangsa, toleransi, saling menghormati, menghargai dan patriotisme.

Jika Pancasila menjadi ideologi negara berkembang era society 5.0, maka nilai nasionalisme relevan. Nilai dasar pemanfaatan Pancasila sebagai negara merupakan salah satu pengembangan soft skill peradaban era society 5.0 (Junanto and Afriani 2016). Jika sistem dan proses pendidikan didasarkan pada esensi nilainilai Pancasila, maka keberadaan Pancasila dapat mendukung perkembangan era society 5.0. Pendidikan karakter dalam masyarakat sebenarnya tunduk pada norma sosial universal dan telah menjadi penunjang khas budaya nusantara. Integrasi aktivitas budaya dan kearifan lokal membuat setiap orang terbiasa dengan kegiatan ini sarat makna dan nilai. Nilai luhur yang diturunkan dari generasi ke generasi membuatnya mengakar di hati setiap orang. Tentunya nilai luhur tersebut termasuk didalamnya nilai pendidikan karakter yang akan memperkuat karakter setiap orang (Fajarini 2014). 
Nilai karakter dapat diartikan sebagai perilaku pribadi yang kuat tanpa mengutamakan bantuan orang lain. Dampak masa depan adalah sikap inovatif, rasa tanggung jawab, percaya diri, mampu memecahkan masalah dan menguasai keterampilan sesuai dengan kemampuannya sendiri (Karima and Ramadhani 2017). Pada era sekarang ini gaya hidup masyarakat telah mengalami pergeseran paradigma, sehingga gaya hidup masyarakat sangat bergantung pada orang lain, seperti jasa pengetikan, makanan, penelitian, dll. Tentunya berdasarkan ketiga contoh tersebut juga bertambah kemalasannya sendiri, sehingga ia akan terus mengandalkan orang lain.

Kemajuan yang signifikan ini harus mencakup semua kalang di bidang pelatihan, dari tingkat pusat, umum, lokal / kota, hingga satuan pendidikan. Pelibatan orang tua peserta didik dan masyarakat juga merupakan bagian penting dalam gerakan literasi digital sekolah. Ada tujuh motivasi yang melatarbelakangi mengapa pendidikan karakter harus disampaikan, lebih spesifiknya: (1) cara yang paling ideal untuk menjamin anak-anak (mahasiswa) memiliki karakter yang hebat dalam hidupnya; (2) cara-cara mengerjakan prestasi skolastik; (3) beberapa siswa tidak dapat membentuk pribadi yang solid untuk diri mereka sendiri di tempat yang berbeda; (4) kesiapan siswa untuk menerima kelompok atau individu yang berbeda dan dapat hidup dalam masyarakat yang berbeda; (5) berangkat dari akar permasalahan yang diidentikkan dengan masalah moral-sosial, seperti kekasaran, sifat menipu, kebiadaban, pelanggaran tindakan seksual, dan rendahnya sikap kerja keras (belajar); (6) landasan terbaik untuk perilaku di lingkungan kerja; (7) mempelajari sifat-sifat sosial yang penting untuk terciptanya kemajuan manusia.

Perkembangan dan paradigma era society 5.0 telah mengubah sikap dan tindakan komunitas sebelumnya, komunitas seperti ini mengutamakan gotong royong dan kini bergerak ke arah yang lebih individualistis. Perilaku individualistik di era modern dapat dijelaskan sebagai corak hidup yang cenderung didasarkan pada kebebasan pribadi di atas kepentingan bersama, sehingga masyarakat akan hidup acuh tak acuh di lingkungan sekitarnya.

Gerakan literasi digital sekolah diharapkan dapat membentuk karakter siswasiswa di era society 5.0 di sekolah. pembentukan karakter siswa dilengkapi dengan 
pengembangan kemampuan komputerisasi di sekolah, dengan membuat kecenderungan menonton tayangan tentang pengajaran melalui infokud tayangan 15 menit menjelang dimulainya ilustrasi, kemudian, pada saat itu, siswa membuka situs yang telah instruktur mengatur koneksi ke (untuk situasi ini situs tentang sekolah yang sekarang populer secara lokal), di PC khusus mereka di lab PC. Pengembangan literasi sekolah bertujuan untuk memperluas inspirasi siswa dalam belajar, mendorong pemikiran inovatif siswa dan mendorong kepercayaan siswa dan instruktur. Sehingga nantinya mereka bisa menjadi mahasiswa luar biasa yang mampu bersaing di era globalisasi saat ini.

Di era pengembangan society 5.0, ada kebutuhan dan kebutuhan yang besar akan karakter atau individu yang berkarakter lengkap. Ini mengingat era society 5.0 yang memiliki banyak kekurangan pribadi dalam hal kelengkapan dan wawasan yang luas. Ketiadaan integritas tersebut akan muncul akibat pengaruh gaya hidup dan gaya Barat yang menurut penulis juga melemahkan budaya yang ada di tanah air.

Melalui apa yang harus ditanamkan oleh setiap orang di Indonesia, pemerintah mencanangkan 18 (delapan belas) nilai pendidikan moral, yaitu agama, kejujuran, toleransi, disiplin, kerja keras, inovasi, kemandirian, demokrasi, rasa ingin tahu, semangat kebangsaan, cinta tanah, hargai prestasi, persahabatan / komunikasi, cinta damai, suka membaca, peduli lingkungan, peduli pada masyarakat dan tanggung jawab. Semua itu bersumber dari kebudayaan nasional Indonesia, dan bangsa Indonesia harus diwariskan dari generasi ke generasi sebagai negara yang bercirikan bangsa (Permendikbud No 20 Tahun 2018 2018).

Kaitannya dengan penguatan literasi digital, tentunya seperti 18 nilai pendidikan karakter, akan mampu memperkuat makna literasi digital, sehingga dapat dipertahankan di dunia digital, khususnya dalam perdebatan sosial. media. Dengan nilai-nilai agama, seseorang akan dapat lebih mengontrol dirinya dengan menerapkan ajaran agamanya sehingga tidak mudah terpengaruh oleh hal-hal yang belum tentu benar. Buat dan bagikan informasi dengan jujur. Menjaga toleransi terhadap perbedaan ras, agama, pendapat, dll. Disiplin, ketekunan, kreativitas, dan kemandirian penggunaan media digital untuk bekerja dengan menghasilkan karya 
yang positif. Selalu berpegang pada nilai-nilai demokrasi yaitu tidak menggunakan kemauan dalam aktivitas sosial di dunia digital.

\section{KESIMPULAN}

Dari hasil tinjauan, cenderung disimpulkan bahwa Penguatan Pelatihan Karakter melalui literasi dapat menjadi prosedur untuk menghadapi era society 5.0. Melalui literasi digital, upaya untuk membentengi lima karakter utama, tepatnya: Nasionalisme, Kemandirian, Religiusitas, integritas dan gotong royong bersama dapat ditumbuhkan dengan sukses dan metodis. Penyelenggaraan pendidikan, khususnya kemahiran tingkat lanjut, dilakukan secara terencana dengan mengikutsertakan semua perkumpulan yang beridentitas dengan kelas, sekolah dan daerah setempat.

Penelitian ini mengungkapkan bahwa media pembelajaran era society 5.0 adalah media pembelajaran berbasis teknologi dimana media pembelajaran yang tepat adalah media sosial yang notabene sudah sangat familiar di kalangan mahasiswa. Penelitian ini mengungkapkan bahwa media sosial merupakan media pembelajaran yang relevan dalam mendidik generasi saat ini. Penggunaan media sosial sebagai media pembelajaran dan pengawasan siswa merupakan langkah yang tepat mengingat generasi saat ini sebenarnya sangat akrab dengan media sosial, bahkan porsi dunia maya mereka terkadang lebih besar dari porsi dunia nyata mereka.

Kegiatan literasi informasi dapat dikembangkan dengan model multi literasi, artinya siswa tidak hanya diajarkan untuk mengikuti standar literasi informasi, tetapi juga perlu dibekali dengan literasi lain di lingkungan digital saat ini. Informasi yang dihasilkan dapat menjadi pengetahuan baru dan mampu membangun masyarakat yang lebih baik dengan menggunakan perangkat digital secara etis, santun, bertanggung jawab dengan memperhatikan aspek sosial, budaya, ekonomi dan hukum yang melingkupi informasi digital. Budaya literasi tradisional seperti menulis, membaca dan mendengarkan masih dibutuhkan di lingkungan digital untuk meningkatkan kemampuan literasi digital bagi generasi digital natives. 
Literasi digital adalah keahlian dalam berpikir tingkat yang tak terbantahkan, sebagai pendukung dalam mengembangkan prestasi di bidang akademis, pribadi dan profesional, memasuki era Society 5.0 siswa diperlukan untuk mendominasi dunia digital untuk masa depan yang cerah mereka perlu mempersiapkan diri untuk kerangka pembelajaran yang lebih kreatif dalam bidang pengajaran dan siap untuk menyesuaikan dengan rencana pendidikan sesuai dengan perbaikan mekanis yang nantinya dapat membawa siswa ke dunia kerja yang canggih.

Warga Negara yang mengonsumsi media, semakin perlu memahami bahwa pendidikan, baik media dan digital itu penting. Hal ini karena data di media semakin beragam, inovasi digital berkembang dan juga mencakup investasi daerah yang lebih luas. Harus ada perhatian terhadap media dan pembelajaran digital mulai dari tingkat sekolah dasar hingga universitas. Kemahiran tingkat lanjut juga mendorong kemajuan informasi dan meningkatkan kemampuan seseorang dalam mengartikan teks media dan memanfaatkan inovasi, serta kemampuan untuk berkolaborasi baik di antara klien dan inovasi serta di antara klien dan penerima konten.

Pendidikan karakter merupakan landasan pembentukan karakter atau kepribadian siswa. Yang bisa dilakukan untuk memperkuat pendidikan karakter adalah dengan mengintegrasikan guru, orang tua dan pihak lain ke dalam satu tubuh untuk menyambut datangnya era society 5.0. Melalui demonstrate pembelajaran yang komprehensif diharapkan dapat memberikan dampak yang baik.

\section{DAFTAR PUSTAKA}

Adyawanti, Tety, A. Pendahuluan, and Biro Pusat. 2016. "LITERASI MEDIA." ProListik.

Alhefeiti, Fatmah SAif Obaid. 2018. "A Human-Centered Society That Balances Economic Advancement with the Resolution of Social Problems by a System That Highly Integrates Cyberspace and Physical Space." (November).

Altınay, Zehra, Ebba Ossiannilsson, Mustafa Ozhan Kalaç, Gülsün Başarı, Ali Aktepebaş1, and Fahriye Altınay. 2016. "Establishing a Framework on OER Practices for ICT Competence of Disabled Citizens." Turkish Online Journal of Educational Technology.

Andriani, Rike, and Rasto Rasto. 2019. "Motivasi Belajar Sebagai Determinan Hasil Belajar Siswa." Jurnal Pendidikan Manajemen Perkantoran. doi: 10.17509/jpm.v4i1.14958.

Atarodi, Alireza, Meisam Dastani, Mohammad Ghorbani, and Ahmadreza Atarodi. 
2021. "The Role of Mass Media and Social Media in Developing Awareness of Self-Care Behavior against the Outbreak of Covid-19." Library Philosophy and Practice.

Atiah, Nurma. 2020. "Pembelajaran Era Disruptif Menuju Masyarakat 5.0." Prosiding Seminar Nasional Pendidikan Program Pascasarjana Universitas Pgri Palembang 10 Januari 2020.

Awulloh, Abdul, and Khofiyati Latifah. 2021. "Urgensi Pendidikan Karakter Dalam Menghadapi Era Society 5 . 0 Study." 348-53.

Bawden, David. 2008. "Digital Literacies: Concepts, Policies and Practices." in Names.

Çam, Emre, and Mübin Kiyici. 2017. "Perceptions of Prospective Teachers on Digital Literacy." Malaysian Online Journal of Educational Technology.

Chan, Banny S. K., Daniel Churchill, and Thomas K. F. Chiu. 2017. "Digital Literacy Learning In Higher Education Through Digital Storytelling Approach.” Journal of International Education Research (JIER). doi: 10.19030/jier.v13i1.9907.

English, Jacob Alan. 2016. "A Digital Literacy Initiative in Honors: Perceptions of Students and Instructors about Its Impact on Learning and Pedagogy." Journal of the National Collegiate Honors Council.

Fajarini, Ulfah. 2014. "PERANAN KEARIFAN LOKAL DALAM PENDIDIKAN KARAKTER." SOSIO DIDAKTIKA: Social Science Education Journal. doi: 10.15408/sd.v1i2.1225.

Fitriarti, Etik Anjar. 2019. "URGENSI LITERASI DIGITAL DALAM MENANGKAL HOAX INFORMASI KESEHATAN DI ERA DIGITAL." Metacommunication: Journal of Communication Studies. doi: 10.20527/mc.v4i2.6929.

Gillen, Julia. 2014. Digital Literacies.

Goodfellow, Robin. 2011. "Literacy, Literacies and the Digital in Higher Education." Teaching in Higher Education. doi: 10.1080/13562517.2011.544125.

Gruszczynska, Anna, Guy Merchant, and Richard Pountney. 2013. "Digital Futures in Teacher Education': Exploring Open Approaches towards Digital Literacy." Electronic Journal of E-Learning.

Hague, Cassie, and Sarah Payton. 2010. "Digital Literacy across the Curriculum Key to Themes: A Futurelab Handbook." Futurelab.

Hayashi, Hisanori, Hisashi Sasajima, Yoichi Takayanagi, and Hirco Kanamaru. 2017. "International Standardization for Smarter Society in the Field of Measurement, Control and Automation." in 2017 56th Annual Conference of the Society of Instrument and Control Engineers of Japan, SICE 2017.

Irianti, Leni. 2020. “Teachers' Perception on Flipped Classroom Model in Digital Literacy Era." ELT-Lectura. doi: 10.31849/elt-lectura.v7i2.3685.

Ismail, Nurzali. 2015. "The Integration of New Media in Schools: Comparing Policy 
with Practice." International Education Studies. doi: 10.5539/ies.v8n12p231.

Jimoyiannis, Athanassios, and Maria Gravani. 2011. "Exploring Adult Digital Literacy Using Learners' and Educators' Perceptions and Experiences: The Case of the

Second Chance Schools in Greece.” Educational Technology and Society.

Jones, Chris, Ruslan Ramanau, Simon Cross, and Graham Healing. 2010. "Net Generation or Digital Natives: Is There a Distinct New Generation Entering University?" Computers and Education. doi: 10.1016/j.compedu.2009.09.022.

Junanto, Tulus, and Rachmi Afriani. 2016. "Implementasi Digital-Age Literacy Dalam Pendidikan Abad 21 Di Indonesia." Prosiding Seminar Nasional Pendidikan Sains.

Karima, Maulana Kaulan, and Ramadhani. 2017. "Peran Pendidikan Dalam Mewujudkan Generasi Emas Indonesia Yang Bermartabat." Jurnal Program Studi Pendidikan Ilmu Pengetahuan Sosial.

Kennedy, Gregor E., Terry S. Judd, Anna Churchward, Kathleen Gray, and Kerri Lee Krause. 2008. "First Year Students' Experiences with Technology: Are They Really Digital Natives?" Australasian Journal of Educational Technology. doi: 10.14742/ajet.1233.

Kirchoff, Jeff. 2017. "Using Digital Comics to Develop Digital Literacy: Fostering Functionally, Critically, and Rhetorically Literate Students." Texas Journal of Literacy Education.

Koltay, Tibor. 2011. "The Media and the Literacies: Media Literacy, Information Literacy, Digital Literacy." Media, Culture and Society. doi: 10.1177/0163443710393382.

Komara, Endang. 2018. "Penguatan Pendidikan Karakter Dan Pembelajaran Abad 21." SIPATAHOENAN: South-East Asian Journal for Youth, Sports \& Health Education.

Kurniawan, Machful Indra. 2015. "Tri Pusat Pendidikan Sebagai Sarana Pendidikan Karakter Anak Sekolah Dasar." PEDAGOGIA: Jurnal Pendidikan. doi: 10.21070/pedagogia.v4i1.71.

McDougall, Julian, Mark Readman, and Philip Wilkinson. 2018. "The Uses of (Digital) Literacy." Learning, Media and Technology. doi: 10.1080/17439884.2018.1462206.

Nana, Nana, and Endang Surahman. 2019. "Pengembangan Inovasi Pembelajaran Digital Menggunakan Model Blended POE2WE Di Era Revolusi Industri 4.0." Prosiding SNFA (Seminar Nasional Fisika Dan Aplikasinya). doi: 10.20961/prosidingsnfa.v4i0.35915.

Nelson, Klara, Marcy Courier, and Gilbert Joseph. 2011. "An Investigation of Digital Literacy Needs of Students." Journal of Information Systems Education.

Olsson, Lena, and Eva Edman-Stålbrant. 2008. "Digital Literacy as a Challenge for Teacher Education." in Learning to Live in the Knowledge Society. 
Ozdamar-Keskin, Nilgun, Fatma Zeynep Ozata, Kerim Banar, and Karl Royle. 2020. "Examining Digital Literacy Competences and Learning Habits of Open and Distance Learners." Contemporary Educational Technology. doi: 10.30935/cedtech/6140.

Özdemir, Vural, and Nezih Hekim. 2018. "Birth of Industry 5.0: Making Sense of Big Data with Artificial Intelligence, 'the Internet of Things' and Next-Generation Technology Policy." OMICS A Journal of Integrative Biology. doi: 10.1089/omi.2017.0194.

Permendikbud No 20 Tahun 2018. 2018. "Penguatan Pendidikan Karakter Pada Satuan Pendidikan Formal.” Kementerian Pendidikan Dan Kebudayaan Republik Indonesia.

Purandina, I. P. Y. 2020. “'New Normal': It's Time to Become More Independent in Developing Soft Skills and Character Education in Higher Education Level (Indonesian Context)." Jayapangus Press Books.

Raharja, Handy Yoga. 2019. "Relevansi Pancasila Era Industry 4.0 Dan Society 5.0 Di Pendidikan Tinggi Vokasi." JOURNAL OF DIGITAL EDUCATION, COMMUNICATION, AND ARTS (DECA). doi: 10.30871/deca.v2i1.1311.

Rahman, Fatur. 2019. "Society 5.0: Konsep Peradaban Masa Depan - HMIF ITB Tech - Medium." Medium.Com.

Ramdani, Dede, Deasy Nurma Hidayat, Asep Sumarna, and Icmiati Santika. 2020. "Ideal Character of Muslim Generation of Industrial Revolution Era 4.0 and Society 5.0." Jurnal Iqra' : Kajian Ilmu Pendidikan. doi: 10.25217/ji.v5i1.644.

Robertson, Margaret, Andrew Fluck, Ivan Webb, and Barton Loechel. 2004. "Classroom Computer Climate, Teacher Reflections and 're-Envisioning' Pedagogy in Australian Schools." Australasian Journal of Educational Technology. doi: 10.14742/ajet.1352.

Rohman, Fathur. 2016. "Analisis Meningkatnya Kejahatan Cyberbullying Dan Hatespeech Menggunakan Berbagai Media Sosial Dan Metode Pencegahannya." Sniptek 2016.

Son, Jeong Bae, Sang Soon Park, and Moonyoung Park. 2017. "Digital Literacy of Language Learners in Two Different Contexts." JALT CALL Journal. doi: 10.29140/jaltcall.v13n2.213.

Song, Ah-Young. 2017. "Critical Media Literacies in the Twenty-First Century: Writing Autoethnographies, Making Connections, and Creating Virtual Identities." Journal of Media Literacy Education. doi: 10.23860/jmle-2017-9-15 .

Tang, Chun Meng, and Lee Yen Chaw. 2016. "Digital Literacy: A Prerequisite for Effective Learning in a Blended Learning Environment?" Electronic Journal of E-Learning.

Traxler, John. 2018. "Digital Literacy: A Palestinian Refugee Perspective." Research in Learning Technology. 
Wang, Qiyun. 2008. "A Generic Model for Guiding the Integration of ICT into Teaching and Learning." Innovations in Education and Teaching International. doi: 10.1080/14703290802377307.

Yoga Purandina, I. Putu, and I. Made Astra Winaya. 2020. "Pendidikan Karakter Di Lingkungan Keluarga Selama Pembelajaran Jarak Jauh Pada Masa Pandemi COVID-19." Cetta: Jurnal Ilmu Pendidikan. doi: 10.37329/cetta.v3i2.454. 